\title{
Ducted fans for hybrid electric propulsion of small aircraft
}

\author{
Daniel Weintraub $^{1}\left[\right.$ ] Jan Koppelberg ${ }^{1} \cdot$ Jo Köhler $^{1} \cdot$ Peter Jeschke $^{1}$
}

Received: 3 February 2021 / Revised: 10 November 2021 / Accepted: 8 February 2022 / Published online: 27 February 2022

(c) The Author(s) 2022

\begin{abstract}
This paper presents a method for modeling ducted fan propulsion systems for hybrid-electrically driven small aircraft based on mean line flow analysis methods. Studies of the essential design parameters provide the basis for a discussion of potential advantages when compared to free propellers, as well as possible new fields of application for the ducted fan. A two-seater aircraft, equipped with two ducted fans powered by a combustion engine and additionally by a parallel hybrid electric start-boost drive, is used as a reference application case. The fan performance characteristics are described with the aid of aero mean line flow analysis methods and semi-empirical loss correlations. Physics-based methods are applied to assess the nacelle drag and noise emissions. The combustion engine and electric motor performance are described using maps. The ducted fan design variables are investigated to identify the main trade-offs and favorable designs for the target aircraft mission, with special attention to noise. The results show that the performance of fixed pitch fans benefits strongly from hybridization. Ducted fans can also operate considerably more quietly than is required by current certification standards. The physics-based design method presented here can be used for conceptual design and performance prediction of ducted fan propulsion systems, which may be especially interesting if low noise emissions are required.
\end{abstract}

Keywords Hybrid $\cdot$ Electric $\cdot$ Propulsion $\cdot$ Noise $\cdot$ Ducted fan $\cdot$ Fixed pitch fan $\cdot$ Conceptual design

\section{List of symbols}

Symbols

$\dot{m} \quad$ Mass flow

$\kappa \quad$ Isentropic exponent

$\rho \quad$ Fluid density

A Cross-sectional area

$C_{f g} \quad$ Gross thrust coefficient

$F_{N} \quad$ Net thrust

$H_{P} \quad$ Degree of hybridization

$M \quad$ Mach number

$N \quad$ Spool speed

$P \quad$ Shaft power

Daniel Weintraub

weintraub@ist.rwth-aachen.de

Jan Koppelberg

koppelberg@ist.rwth-aachen.de

Jo Köhler

j.koehler@ist.rwth-aachen.de

Peter Jeschke

jeschke@ist.rwth-aachen.de

1 Institute of Jet Propulsion and Turbomachinery, RWTH Aachen University, Templergraben 55, 52062 Aachen, Germany

$\begin{array}{ll}p & \text { Static pressure } \\ u & \text { Blade circumferential speed } \\ v & \text { Flow speed, absolute } \\ w & \text { Flow speed, relative to rotor }\end{array}$

Abbreviations

BPF Blade passing frequency

EM Electric motor

GA General aviation

ICE Internal combustion engine

ISA International standard atmosphere

SL Sea level

TAS True airspeed

TOC Top of climb

\section{Introduction}

Prompted by progress in the field of electric drive systems, numerous new small aircraft and propulsion system designs have been developed in recent years. Hybrid and electric propulsion systems are opening up design freedoms and enabling new aircraft concepts $[5,7,33]$. When installed on conventional aircraft, they are potentially useful in reducing fuel consumption and emissions. Additional secondary 
advantages include noise reduction and increased operational flexibility.

Noise reduction is of great importance to ensure that future small aircraft can be operated and tolerated in urban environments. Aircraft, and hence propulsion noise, therefore needs to be considered early on, at the conceptual design stage. In this regard, the ducted fan offers potential advantages over the free propeller, typically employed in general aviation (GA) aircraft. This is due to the following: non-propagation of rotor alone noise outside the duct; a variety of rotor blade and stator vane design features usable to minimize noise; noise shielding options; possible use of acoustic liners; and a stronger absorption of higher frequency noise. All of the aforementioned reduce noise compared to the conventional unrestricted radial emission of propeller noise [24, 35].

Previous GA aircraft with ducted fans include the Norman Islander [12, 44], the Fanliner [2], the Fanjet [18], and a number of other prototypes [36]. However, no small GA aircraft in series production features ducted fan propulsion due, in part, to its adverse effect on efficiency, as well as nacelle integration problems. More recently, several new projects have been and are being pursued in this field [4, 19, 22], among them the Airbus E-Fan [27] and the Silent Air Taxi [16].

A comprehensive overview of low-speed axial flow fan design methods and their state-of-the-art is given by Castegnaro [11] and Zhang and Barakos [46]. A widely used design tool is the Ducted Fan Design Code (DFDC) by Youngren, Drela, and Sanders [45]. Physics-based noise analysis methods have been developed and applied to ducted fans by Jaron [26] and Moreau [34], who in their studies concentrated on turbofan engines for airliners. Recently, these methods have also been applied to ducted fans for aircraft in the GA domain by Schade et al. [37].

The ducted fan has a different operating behavior from the free propeller. In particular, when high blade numbers are used, e.g., for noise reduction, it is difficult to incorporate a blade pitch control mechanism. This complicates the matching of a combustion engine and the fan: During cruise, the fan spool speed is much higher than at take-off. Hence, the combustion engine is forced to operate below its maximum speed at take-off when most engine power is required. A parallel hybrid propulsion system can solve this with an electric motor supplying additional shaft power at take-off.

A presentation of the conceptual design approach to such a parallel hybrid ducted fan propulsion system is given here, with particular attention to noise prediction. The design method is presented first, followed by the algorithms and physical models implemented to calculate propulsion system performance and noise. Fan stage design and performance analysis are based on mean line methods, which enable comprehensive design parametric studies that are necessary for acoustic optimization. Next, a propulsion system design for a reference application is developed. Finally, the influence of the ducted fan's main design variables on performance and emitted noise are investigated in trade studies and the essential trade-offs of ducted fan design are discussed.

\section{Conceptual design method}

The propulsion system under consideration in this publication is shown in Fig. 1. It can be divided into the ducted fans and the powertrain, which are modeled and analyzed separately.

\subsection{Powertrain design}

The powertrain consists of an internal combustion engine (ICE) and an electric motor (EM), as well as the shafts and gearboxes necessary to transmit power to the fans. Power contributions can be varied in this hybrid powertrain, which offers operational flexibility. The operating behavior of its components, i.e., their operating limits and efficiencies as a function of torque, rotational speed, and ambient conditions, is included in the system simulation by means of component maps and transmission efficiencies.

At the conceptual design stage, different off-the-shelf ICEs can be chosen and basic design variables of the EM can be varied while studying the influence of these choices on the operating behavior of the propulsion system, including operating strategy variations. In many systems, a reduction gearbox is placed between the engine and the propulsor. Since the main focus here is on the ducted fan, no more detailed design of these components has been conducted and no further design parameters of the powertrain have been

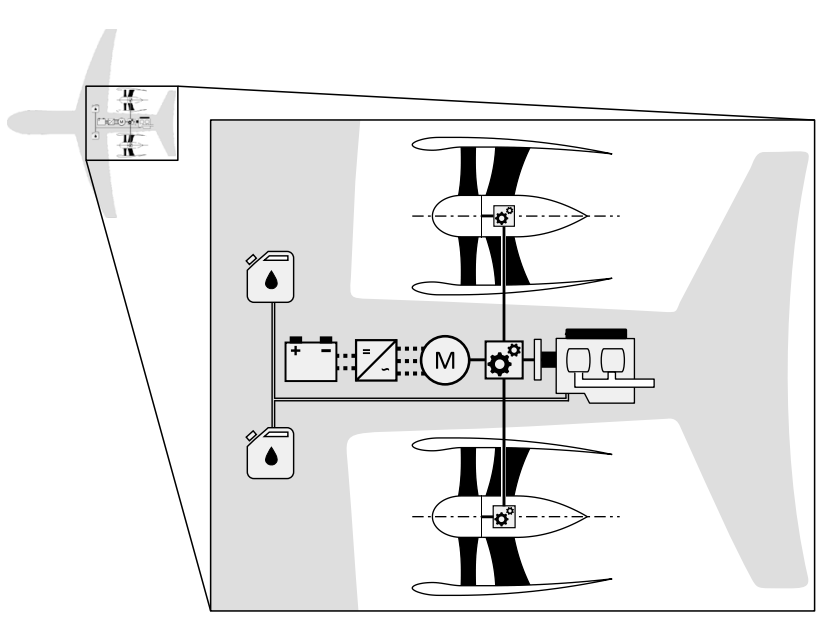

Fig. 1 Parallel hybrid electric propulsion system architecture under consideration: battery, inverter, electric motor, fuel tanks, combustion engine, and power transmission to two ducted fans 
varied. As such, no in-depth physical models of the powertrain are required.

\subsection{Ducted fan design variables}

The main design variables of the ducted fan are shown in Fig. 2. Only one fan is considered here, assuming that both fans can be designed identically and then show the same operational performance.

The fan can be regarded as a single-stage axial compressor. Mean line flow analysis methods are used for its design and performance analysis. The mean line velocity triangles of the fan are characterized by five design variables: the stage loading; enthalpy reaction; flow coefficients of rotor and stator; and the mean line rotational blade speed.

Of these variables, three are implicitly fixed by the boundary conditions of the design task: Except for special operating conditions, the fan features uniform axial inflow and, ideally, also axial outflow to maximize thrust generation efficiency. It can therefore be designed as a repeating stage, with the simplifying assumptions described in Sect. 3, including constant axial flow speed. Furthermore, the relationship between flow and loading is determined by the nozzle characteristic, i.e., primarily its cross-sectional area. In this way, only two degrees of design freedom remain when designing the mean line velocity triangles.

The design variable choice can be adapted to suit the requirements of the study. Non-dimensional, universally applicable variables are often preferred, due to their general applicability, but a different approach is taken here: Blade tip speed and design shaft power are chosen as the main fan

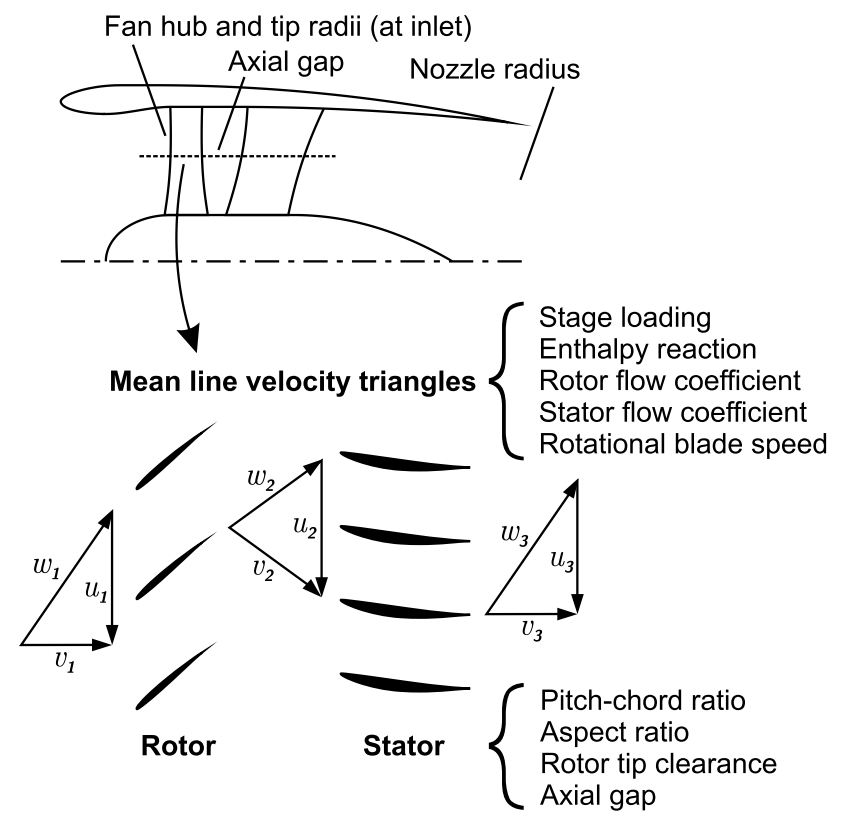

Fig. 2 Ducted fan design variables stage design variables. The blade tip speed has implications for loading, stresses and noise generation. The shaft power is provided primarily by the ICE with a performance characteristic depending on spool speed which is different from typical turbomachines, since

$P_{\text {ICE }} \propto N_{\text {ICE }} \quad$ while

$P_{\text {Fan }} \propto N_{\text {Fan }}^{3}$

This presents a challenge when designing ICE-powered fans without blade pitch adjustment, and this challenge can be more easily addressed when the propulsion system design starts off by choosing a fixed ICE operating point in its performance map, which then sets the fan shaft power.

Additional design parameters of the fan are: the pitch-chord ratio and aspect ratio of the blades and vanes; rotor tip clearance; and the axial gap. These are often determined not solely on the basis of aerodynamics, but are also influenced by acoustics, structural mechanics, construction requirements, and other practical considerations.

\subsection{Design and analysis algorithm}

The powertrain component design is driven by requirements of different flight mission operating points, as is normal for aircraft propulsion systems. A multi-point design algorithm is applied to meet the varying component demands, inspired by the GasTurb software [20]. This begins with the aerodynamic design of the fan stage, e.g., for optimum cruise efficiency with take-off and climb requirements as boundary conditions. Next, the electric components are sized. In a boost application, these are operated for a short time only, e.g., take-off and initial climb, and transient heat soakage can be utilized to improve their power density. The ICE is considered in less detail. It is included in the calculation as an off-the-shelf component with a given performance map, i.e., torque and efficiency as a function of rotational speed and possibly also altitude, unless the engine is turbo-normalized. The nacelle is designed for critical operating conditions, such as take-off in strong crosswinds and in-flight engine shutdown. Since this is strongly linked to the aircraft design, it is only discussed briefly here. The overall design and analysis algorithm is visualized in Fig. 3.

\subsubsection{Ducted fan design point}

In principle, the ducted fan design point calculation follows the flow channel, starting with the design point ambient conditions and a given intake pressure loss. The fan stage mean line design is determined from uninstalled upstream conditions and the following design variables: 


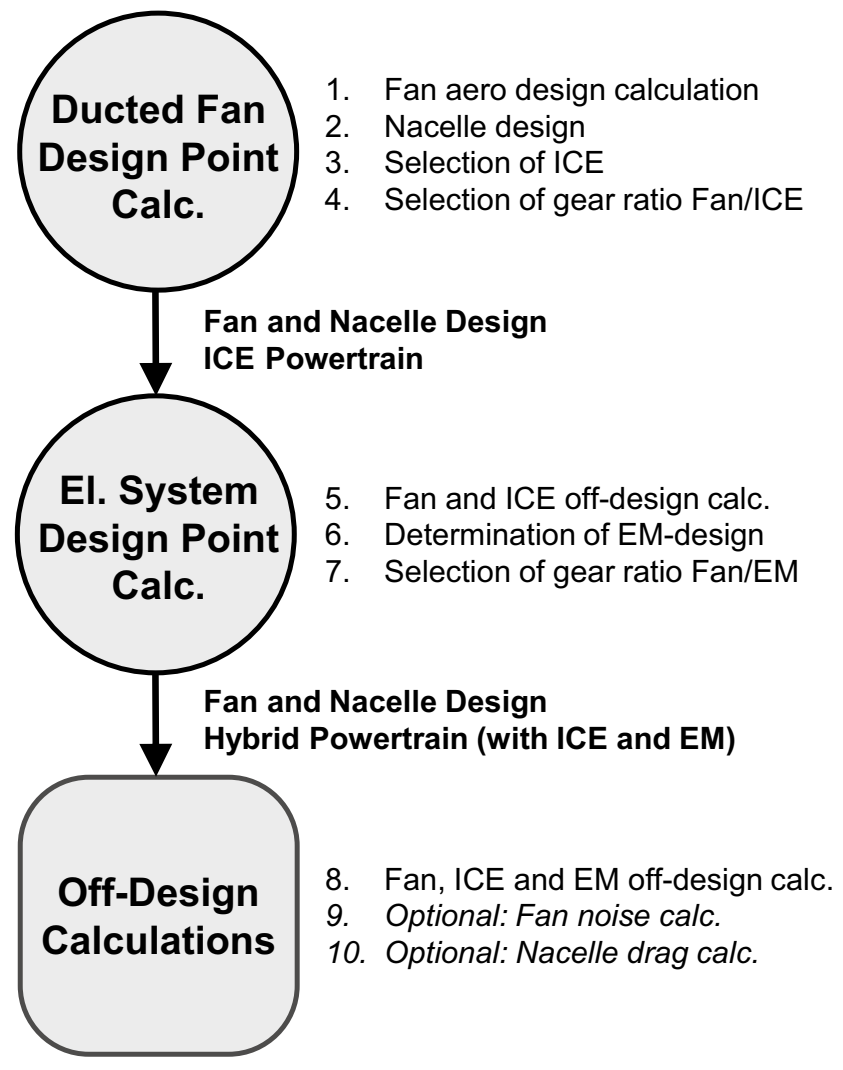

Fig. 3 Algorithm of propulsion system design and off-design performance calculations

- Fan hub and tip diameter

- Blade tip speed

- Design point shaft power

- Blade and vane pitch-chord ratio

- Blade and vane aspect ratio

- Nozzle/fan diameter ratio.

An initial estimate of the fan rotor flow coefficient is made. Being implicitly fixed by the nozzle characteristic, this is not an independent design variable, but serves as a design iteration variable to reconcile fan and nozzle mass flow. The fan efficiency is determined on the basis of loss correlations which are described in Sect. 3. With a given exit duct pressure loss, it is possible to calculate the conditions at the nozzle exit. From the cross-sectional area of the nozzle and the exit static pressure, a mass flow can then be determined.

At first pass, the nozzle exit mass flow does not correspond to the value of the fan mean line design, i.e., the fan mass flow as product of fan inlet axial flow velocity, density, and cross-sectional area. The difference between these two mass flow values is the design iteration target. A root-finding algorithm is applied to find the flow coefficient for which this mass flow error vanishes. As such, all mean line design variables are fixed.
A mixed vortex design, as described by Dixon and Hall [15], is used to determine the flow angles over the entire blade height. The numerical solution algorithm presented by Lewis [31] is adapted for this purpose. Based on the known flow angles, NACA 65-series profiles are developed in conformity with the Lieblein design method [32] for incidence free flow, as presented by Carolus [10].

Next, the nacelle pre-design is conceived. The nacelle cross section is prescribed by a number of non-dimensional nacelle design parameters, which-using empirical correlations-determine the intake pressure losses and installation drag, as described in Sect. 3.

The powertrain design calculation is based on the number of ducted fans powered by one powertrain, the ICE speed at the fan design point, and the power transmission efficiency. These parameters determine the required shaft power and hence also torque of the ICE. This, in turn, defines the ICE operating point in its map and, therefore, efficiency and fuel flow.

With that, the design point calculation is complete. Its output comprises the fan blade and vane preliminary design, its efficiency and net thrust, as well as the transmission gear ratio, ICE efficiency, and fuel consumption at this operating point.

\subsubsection{Design of the electric propulsion system}

The electric design point of the powertrain would typically be selected to reflect a high or the highest power demand, e.g., at maximum electric boost during initial climb. The design point calculation of the electrical system is based on an off-design calculation of the previously designed ducted fan and ICE propulsion system. Similar to the aerodynamic design point, this starts with a definition of the ambient conditions and intake pressure loss. A prescribed fan or ICE spool speed can set the operating point. Alternatively, instead of a fixed spool speed, a choice can be made to attain a predefined net thrust, for example.

Fan performance is again evaluated using mean line analysis methods, now based on the given spool speed and blade and vane geometry. The flow coefficient again serves as an iteration variable to reconcile fan and nozzle mass flows. In this way, the fan operating point and shaft power requirement are set. The degree of hybridization

$H_{P}=\frac{P_{\mathrm{EM}}}{P_{\mathrm{ICE}}+P_{\mathrm{EM}}}$

reflects the shaft power share of electric motor. This sets the ICE operating point and fuel consumption and hence also EM shaft power, as well as EM electric power.

Further input parameters for the electric design point comprise the EM design speed and efficiency. Finally, an 
EM map reflecting the operating behavior of the machine type under consideration is provided, along with a scaling reference point in this map. The map is then scaled, so that the scaling reference point properties match the EM design point properties in terms of speed, torque, and efficiency. Afterwards, this scaled map can be used in off-design calculations to describe the EM off-design behavior.

The output of the electric design point calculation corresponds to the design point output, extended by electrical system properties and power consumption.

\subsubsection{Off-design calculations}

Having completed the aforementioned design steps, all design parameters are then defined, so that arbitrary offdesign calculations can be performed. The required input parameters for each off-design point are: the ambient conditions; power setting as spool speed or thrust requirement; degree of hybridization; and installation conditions, i.e., intake pressure loss and gross thrust coefficient. In so doing, all component operating points are fixed and the performance of the propulsion system can be evaluated over a broad range of operating conditions.

It is likewise possible to calculate fan operating points under standard conditions, constant speed, and with gradually increased throttling, so an estimation of the fan map can be developed. To enable qualitative map width comparisons, a simplified approximation of the map operating limits is made here, based on the tolerated incidences of the mean line NACA 65-profile: The surge line is fixed by assuming that the stall angle of the airfoil equals the maximum possible rotor mean line incidence angle.

\section{Physical modeling}

This section describes the physical modeling of the ducted fan, with the emphasis on loss mechanisms and noise generation. The station nomenclature is shown in Fig. 4. For the performance calculation, homogeneous flow is assumed in all station cross sections, unless otherwise specified.

The fan stage is analyzed using mean line methods. To simplify matters, the hub, tip, and mean line radii are considered constant for pre-design purposes, which can be justified on account of the low pressure ratio of the fan. Later, detailed designs can feature modified end wall contours, for example, to improve stability. For the purpose of this publication, it is estimated that such modifications only have a minor effect on how the operating characteristics are influenced by the main design parameters.

Off-design operating points of the fan are established on the assumption that the flow angle at the trailing edge coincides with the design flow angle. For fans featuring

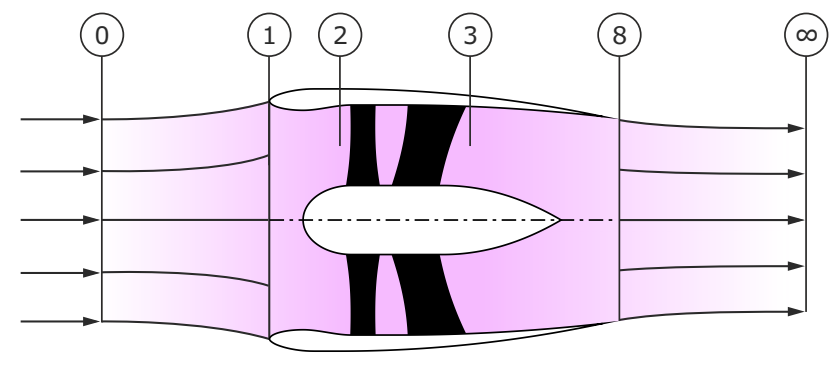

Fig. 4 Station nomenclature

pitch-chord ratios beyond one and operating at high incidence, this is not necessarily the case. The deviation reduces flow turning, hence stage loading, so a correction to the trailing edge flow angle needs to be made. This is performed using the A-factor given by Traupel [42], which is based on potential theory applied to the flow through an infinitely thin cascade of flat-plate airfoils.

Blockage factors are applied to the cross-sectional areas considered for mean line design and a discharge coefficient is applied to $A_{8}$ when calculating $\dot{m}_{8}$. The usual simplification of the ambient pressure $p_{8}$ equaling $p_{0}$ is not utilized, since-given the low pressure ratio of the ducted fan-the nacelle flow field substantially influences $p_{8}$. There is a slipstream contraction downstream of station 8 towards station $\infty$, where $p_{\infty}=p_{0}$, and this contraction is assumed to be constant for all operating conditions. The nozzle exit static pressure is then implicitly given by the nozzle exit total pressure and $M_{8}$ in

$\frac{A_{\infty}}{A_{8}}=\frac{M_{8}}{M_{\infty}}\left(\frac{1+\frac{\kappa-1}{2} M_{8}^{2}}{1+\frac{\kappa-1}{2} M_{\infty}^{2}}\right)^{\frac{\kappa+1}{2(\kappa-1)}}$.

The net thrust of the ducted fan is evaluated as

$F_{N}=A_{8}\left(p_{8}-p_{0}\right)+C_{f g} \dot{m}_{8} v_{8}-\dot{m}_{0} v_{0}$

where all losses of the flow through the ducted fan are accounted for as total pressure losses and so are included in Eq. 5. This, for example, includes duct friction, which is not regarded as a force that counteracts thrust, but instead as total pressure loss which minimizes thrust indirectly. All changes in the momentum of the flow around the nacelle result in drag and are accounted for separately. This is in line with common practice for thrust and drag accounting of turbofan engines; see, for example, [28, 38].

The gross thrust coefficient $C_{f g}$ is approximated analytically utilizing the radially non-uniform axial velocity distribution at station 8 , which follows from the applied mixed vortex design. The momentum of this non-uniform flow is 
set in relation to the momentum of an equal mass flow of equal kinetic energy with radially uniform axial velocity, which would be ideal in terms of propulsive efficiency. This results in

$$
C_{f g}=\frac{\iint_{A_{8}} \rho v_{8}^{2} \mathrm{~d} A}{\sqrt{\iint_{A_{8}} \rho v_{8} \mathrm{~d} A \iint_{A_{8}} \rho v_{8}^{3} \mathrm{~d} A}} .
$$

\subsection{Ducted fan losses and efficiency}

The intake total pressure losses between station 0 and 2 are calculated on the basis of empirical correlations, taking into account lip losses with inner intake lips of elliptical shape according to Blackaby and Watson [3]. These losses are most significant for ambient Mach numbers below 0.1, that is, when the inflow stream tube contracts strongly in front of the ducted fan and flow separations are to be expected in the intake. Wall friction losses in the intake diffusor are accounted for as well, with the method described by Seddon and Goldsmith [38]. All friction coefficients are approximated with flat-plate values from correlations provided by Böswirth et al. [6].

To assess the fan isentropic efficiency, axial compressor mean line loss correlations are used. The losses associated with the flow through the fan can be attributed to a number of loss mechanisms: profile; trailing edge; end wall; tip clearance; secondary; and incidence losses. These are taken into account in the calculation by means of loss coefficients, which are determined depending on stage geometry parameters and the mean line velocity triangles. The coefficients of the individual losses are added up to the total loss of the blade and vane row. Due to their broad applicability, the physics-based loss correlations given by Denton [14] are used for this purpose. Secondary loss is accounted for with a correlation given by Watzlawick [43]. Shock losses are not considered, since they do not occur at the low blade tip speeds investigated.

Nozzle duct pressure losses are calculated on the basis of end wall friction and central body boat tail drag. This drag depends on the central bodies taper ratio, which is captured by an aft body drag correlation given by [23] and converted into a total pressure loss.

\subsection{Nacelle drag}

The nacelle drag is assessed to allow for a more comprehensive evaluation of the results of parametric studies into the ducted fan geometry, e.g., studies of fan diameter. Due to the complex interaction with aircraft aerodynamics, only an initial estimation can be attempted here, mainly including the contributions of additive, friction, and aftbody drag.

Stanhope [39] derived an empirical correlation for the nacelle drag from a series of experiments, which-in this work - is used in the form described as 'fan cowling drag' by Torenbeek [41]. This entails the outer nacelle front featuring an NACA 1-series geometry. The correlation includes a number of non-dimensional geometric parameters and thus allows for an optimization of intake geometry, primarily of intake lip thickness. A thinner lip offers lower drag at high flight speeds, while a thicker lip offers less crosswind sensitivity and lower additive drag rise in case of a propulsion system in-flight shutdown.

The aftbody drag of the nacelle is difficult to predict in the preliminary design, because, to the authors' knowledge, there are no empirical correlations in the literature that fit the application at low flight Mach numbers. The work of Decher et al. [13] leads to the conclusion that the boattail drag coefficients are approximately constant in the range $M_{0}=0.3-0.6$. It is therefore assumed that the correlation presented by Torenbeek [41] is, to a limited extent, transferable to the low flight Mach numbers under consideration here. From this, the base pressure drag coefficient of the nacelle can be estimated to be in the range of 0.005-0.015.

\subsection{Fan noise prediction}

An analytical approach is applied to predict the noise emitted by the fan, which, for this purpose, is considered to operate in an infinite hard-walled duct with constant radius. This simplification can be justified, if the fan case and nacelle have sufficient length compared to the fan diameter and if the fan is sufficiently distanced from the inlet and the nozzle exit. Noise caused by the pressure field of the rotor alone is unable to propagate within this duct. It decays within a short distance inside the duct [35]. Noise generation is mainly caused by rotor-stator interaction and can therefore be ascertained using the method presented by Moreau [34].

As a basis for noise prediction, unsteady-flow perturbations are calculated over the entire blade height, in line with the results of the flow calculation described above. The wake shape development is computed on the basis of the trailing edge boundary layer state. The potential field is determined from blade lift and thickness. Both of these together determine the velocity fluctuations at the rotor blade trailing edge and stator vane leading edge, which can, respectively, be decomposed into a number of sine-shaped velocity perturbations by Fourier analysis. On the basis of the velocity deficit frequency and amplitude, the unsteady rotor and stator lift which cause noise generation can be calculated. This approach takes into account both tonal and broadband noise and is described in more detail by Koppelberg et al. [30]. 
A major share of the noise is generated at the blade passing frequency (BPF) and its harmonics. For certain combinations of blade and vane numbers, noise of the first BPF, and possibly also of the second BPF, cannot propagate in the duct. This marks a cut-off design.

For the evaluation of the noise perceptible to the human ear, an A-weighting filter [1] is applied.

\section{Design studies}

Studies have been conducted to identify the trade-offs when choosing the primary design variables of the ducted fan propulsion system. This section presents the key trade-offs identified. For the purpose of these studies, the design method and propulsion system model described above have been implemented in Matlab R2018b [40].

A number of requirements were determined as a starting point for the design studies: The propulsion system (Fig. 1) should be optimized for a specific application, which-in the example given here-is a two-seater aircraft with a maximum take-off mass of $1000 \mathrm{~kg}$ and a cruising speed of $140 \mathrm{kt}$ true airspeed (TAS) at an altitude of $10 \mathrm{kft}$. This choice of parameters has been made on the basis of a standard GA aircraft, but is otherwise arbitrary. Defining a fixed maximum take-off mass, instead of payload, helps avoid cascading effects of interacting propulsion and aircraft design that would otherwise occur if payload were chosen to be constant. Since the focus of this publication is on ducted fan performance and noise emissions, no attempt is made to establish an optimum overall aircraft and propulsion system design, and propulsion system masses are not considered.

A number of thrust requirements can be deduced from the requirements given above. To this end, a reference aircraft preliminary design has been developed, based on aircraft performance equations and the design of aircraft for similar missions, as described by Brüning et al. [9] and Gudmundsson [21]. It features a wing area of $20 \mathrm{~m}^{2}$, an aspect ratio of 30 , a minimum drag coefficient of 0.0086 , and an optimum $\mathrm{L} / \mathrm{D}$ ratio of 50 . The resulting thrust requirements are listed in Table 1. The take-off thrust requirement is estimated on the basis of a ground run of $210 \mathrm{~m}$. The initial climb thrust requirement is determined from CS-23 Amdt 5 [17], which prescribes a climb gradient of no less than $8.3 \%$. A $600 \mathrm{ft} /$

Table 1 Propulsion system thrust requirements

\begin{tabular}{llll}
\hline Op.-point & Ambient cond. & Airspeed & Thrust-req. \\
\hline Take-off & SL ISA+0 K & $39 \mathrm{kt}$ (TAS) & $1620 \mathrm{~N}$ \\
Init. climb & SL ISA+0 K & $62 \mathrm{kt}$ (TAS) & $1100 \mathrm{~N}$ \\
TOC & $10 \mathrm{kft}$ ISA+0 K & $140 \mathrm{kt}$ (TAS) & $841 \mathrm{~N}$ \\
Cruise & $10 \mathrm{kft}$ ISA+0 K & $140 \mathrm{kt}$ (TAS) & $429 \mathrm{~N}$
\end{tabular}

min climb rate at cruise conditions yields the top of climb (TOC) thrust requirement. The cruise thrust requirement at identical ambient conditions is then easily fulfilled. However, at this point, efficiency should also be optimized.

\subsection{Baseline design}

The reference aircraft could be powered conventionally by a propeller and a $100 \mathrm{~kW}$ combustion engine. For the purpose of the following studies, this aircraft will instead be equipped with the propulsion system of Fig. 1, featuring two ducted fans powered by a common motor and augmented by a parallel hybrid electric start-boost drive. As a reference for the studies, a baseline design for the ducted fan propulsion system was determined that fulfills the above requirements. A Rotax 915 iS A engine was chosen as the key component of the powertrain. It is turbocharged and offers full take-off power up to an altitude of $15 \mathrm{kft}$. Its performance data are publicly available [8]. The max take-off power of $104 \mathrm{~kW}$ can be delivered at 5800 RPM for 5 min. The max continuous power is $99 \mathrm{~kW}$ at $5500 \mathrm{RPM}$. The EM map has been adapted from the Matlab Qss Toolbox [29]. It is generic and can be scaled to match any power demand. Since only takeoff and initial climb are electrically boosted, the operating points in the map are not widely distributed and its topology plays a negligible role in the analysis presented here.

The main design variables presented in Table 2 were chosen as the baseline design for the ducted fan. No variable pitch mechanism is used for the fan blades.

The design point is set at cruise ambient conditions and $107 \mathrm{kt}$ airspeed. Following the design algorithm, the blade profile is determined for incidence free flow under these conditions. The design airspeed is $33 \mathrm{kt}$ below cruise speed, which could likewise have been chosen, to reduce the stagger angle and, in turn, incidence at take-off to a tolerable extent. This is at the expense of a slightly negative incidence at cruise.

Table 2 Baseline design parameter selection

\begin{tabular}{ll}
\hline Design variable & Value \\
\hline Fan tip diameter & $0.600 \mathrm{~m}$ \\
Fan hub diameter & $0.180 \mathrm{~m}$ \\
Blade tip speed & $135 \mathrm{~m} / \mathrm{s}$ \\
Design pt. shaft power & $27 \mathrm{~kW}$ \\
Blade aspect ratio & 2.00 \\
Blade pitch-chord ratio & 2.00 \\
Vane aspect ratio & 1.67 \\
Vane pitch-chord ratio & 1.00 \\
Nozzle/fan diameter ratio & 0.90 \\
Fan design pt. ICE speed & $4680 \mathrm{RPM}$ \\
e-Boost shaft power & $46 \mathrm{~kW}$ \\
\hline
\end{tabular}


The design features 7 rotor blades, 11 stator vanes, and an annular cross section resembling the one shown in Fig. 1. The lower pitch-chord ratio and hence the higher blade count of the stator, compared to the rotor, was chosen to minimize deviation and thus wake swirl, which does not contribute to thrust generation. The resulting blade/vane number combination is favorable, but not optimal for reducing noise emissions, as will be demonstrated in Sect. 4.4.

The ducted fan is connected to the powertrain with a gear ratio of 1.0891. By increasing design tip speed or reducing fan diameter, it would be possible to achieve a gear ratio of 1 , but this offers negligible benefit, since the mechanism necessary for distributing power to two fans can incorporate a transmission at no additional expense.

The thrust which this ducted fan and powertrain combination delivers can be compared to the requirements described in Table 3. The fan can deliver the required take-off thrust only with an electrical boost. Once airborne, however, all thrust requirements can be fulfilled without this e-boost. With a design shaft power of $46 \mathrm{~kW}$, the EM is oversized regarding thrust requirements. However, this helps take full advantage of the boost effect described in the next section. Under initial climb conditions, the thrust requirement is hence far exceeded, which translates into a $19.8 \%$ climb gradient, i.e., a climb rate of $1240 \mathrm{ft} / \mathrm{min}$. This can be advantageous for reducing noise emissions reaching the ground. The initial climb thrust requirement can also be fulfilled without e-boost, which may be advantageous from a certification point of view. The most difficult requirement to meet is the TOC thrust. To limit battery mass, no e-boost is available at TOC. A great deal of ICE power is therefore required and the ICE must be operated at the highest possible speed at TOC to deliver this. This determines the gear ratio.

\subsection{Dual effect of the e-Boost}

Although the $46 \mathrm{~kW}$ of power contributed by the EM is much less than the maximum that the ICE can provide (104 $\mathrm{kW})$, the e-boost increases thrust by roughly $70 \%$ in the two operating points where it has been investigated

Table 3 Comparison of propulsion system thrust requirements and available thrust, provided by the designed baseline propulsion system

\begin{tabular}{llll}
\hline Operating-point & \multicolumn{3}{l}{ Thrust } \\
\cline { 2 - 4 } & Required & Available & Delta (\%) \\
\hline Take-off & $1620 \mathrm{~N}$ & $1366 \mathrm{~N}$ & -16 \\
Take-off (e-Boost) & $1620 \mathrm{~N}$ & $2359 \mathrm{~N}$ & +46 \\
Init. climb & $1100 \mathrm{~N}$ & $1280 \mathrm{~N}$ & +16 \\
Init. climb (e-Boost) & $1100 \mathrm{~N}$ & $2151 \mathrm{~N}$ & +96 \\
Top of climb & $841 \mathrm{~N}$ & $844 \mathrm{~N}$ & \pm 0 \\
Cruise & $429 \mathrm{~N}$ & $844 \mathrm{~N}$ & +97
\end{tabular}

(Table 3). This disproportionately high increase in thrust by the e-boost occurs, because the combustion engine can only deliver its maximum power at its maximum speed. ICE speed, under many ambient conditions however, is constrained by the fan to values far below the maximum speed. The e-boost, which increases the fan and engine speed, then allows the ICE to deliver more power. Because of this dual effect, larger than expected gains in thrust can be achieved with a small e-boost under certain ambient conditions, primarily at low ambient velocities.

Using the ICE map (Fig. 5) and fan map (Fig. 6), this can be explained as follows: Since the gear ratio is fixed, and there is no variable blade pitch, under each set of ambient conditions, there is exactly one operating line for the ducted fan in each map. In the ICE map, it is parabola-shaped, since fan torque is roughly proportional to fan speed squared.

The operating line intersects with the map limit of the ICE the further to the right, the higher the intake ram pressure is. This is because a rising intake total pressure, in combination with the fan pressure ratio, increases nozzle total pressure and mass flow. As a result, the fan is less throttled, which shifts its operating line in the fan map to the right, towards higher speeds. In turn, this shifts the operating line in the ICE map to the right, towards higher speeds and maximum torques.

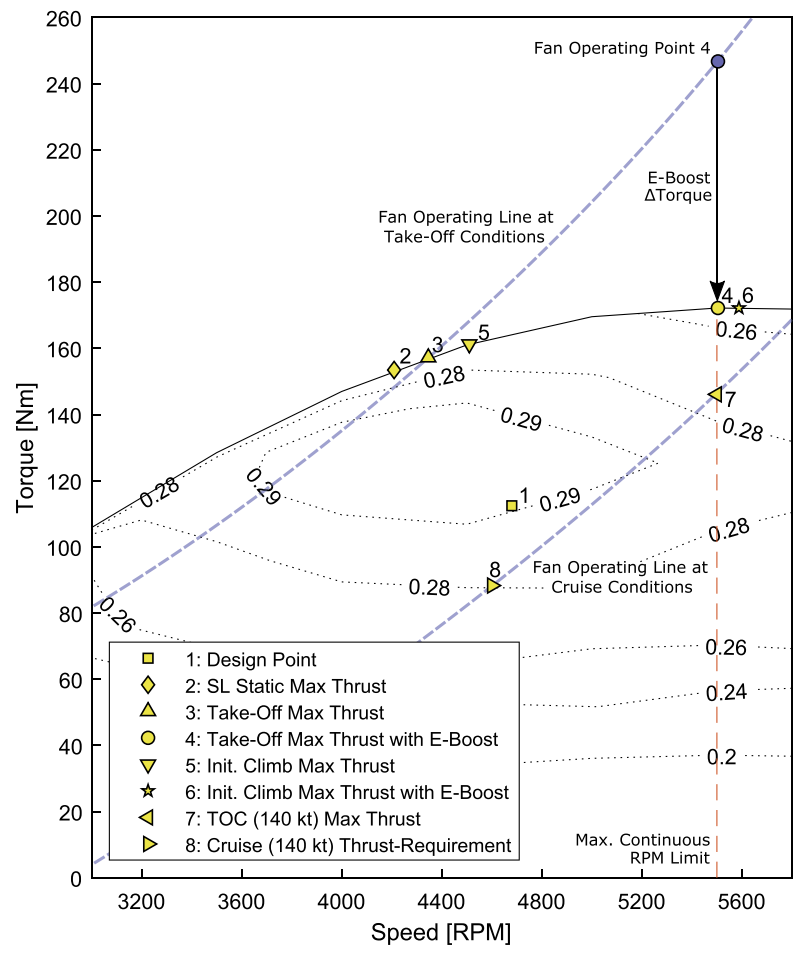

Fig. 5 ICE map based on Rotax 915 iS A [8] with fan design point, various further operating points, max. continuous operating limit at 5500 RPM and fan operating lines at take-off and cruise conditions 


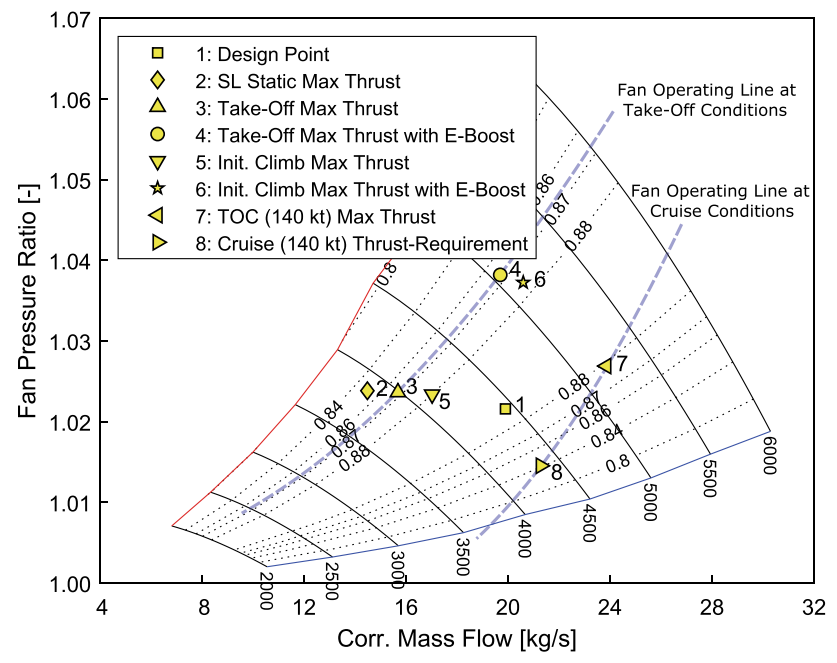

Fig. 6 Predicted fan map with fan design point, various further operating points, and operating lines at take-off and cruise conditions

Conversely, at low inflow velocities or static conditions, relatively high fan pressure ratios are already achieved at low spool speeds. Consequently, the ICE torque limit is reached at speeds below the ICE max speed, where the ICE cannot deliver maximum power. Under such conditions, the e-boost can be particularly useful, increasing thrust greatly.

At sea-level static conditions, for example, the fan is strongly throttled and operates near the surge line. This means that-without the e-boost-fan and ICE speed are low and the ICE cannot deliver its maximum power, but only $68 \mathrm{~kW}$ at $4350 \mathrm{RPM}$. Increased inflow velocity increases fan mass flow and speed; hence, the ICE speed and power can increase during the take-off run with $76 \mathrm{~kW}$ already available at $4510 \mathrm{RPM}$ under initial climb conditions. The e-boost of $46 \mathrm{~kW}$ enables the ICE to operate at a much higher speed of 5590 RPM, where it can deliver $101 \mathrm{~kW}$ under initial climb conditions, i.e., $25 \mathrm{~kW}$ more than without the e-boost. This is an additional benefit of the e-boost: Not only is electrical power supplied to the fan and converted into thrust, but the increased fan speed also enables the ICE to provide substantially more power. In this way, the fan produces substantially more thrust.

This dual effect occurs, because no variable pitch blades are included. With variable pitch, the fan can always be adjusted in a way which enables the ICE to operate at maximum speed and power. However, the blade count and aspect ratio chosen for noise reasons may render a variable pitch mechanism unfeasible. Under such conditions, the aforementioned dual effect can be advantageous.
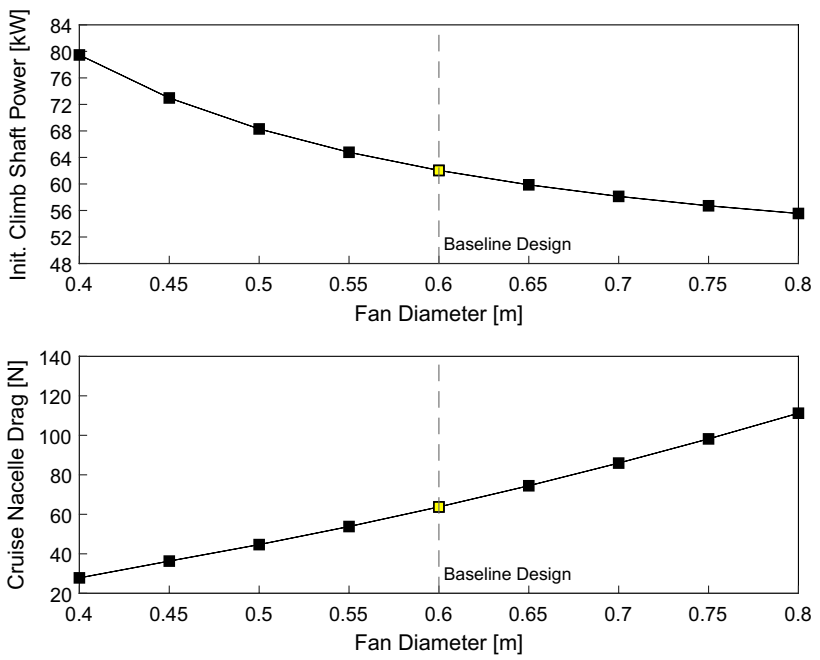

Fig. 7 Influence of fan diameter on shaft power required to meet the initial climb thrust requirement at sea level and on nacelle drag (both nacelles) at cruise (10 kft, $140 \mathrm{kt})$

\subsection{Fan diameter and tip speed}

Five fan design variables are examined with regard to their influence on the efficient fulfillment of thrust requirements, as well as on noise emissions and nacelle drag. The first two parameters to be investigated are fan tip diameter and fan tip speed at the design point. The diameter is essential for ducted fan performance due to its influence on propulsive efficiency, especially at low flight speeds, and so is considered first.

The impact of varying fan diameter and tip speed on the propulsion system performance is illustrated for the operating points described above. All other parameters are kept constant at the values set out in Table 2, including the fan hub diameter. The hub diameter is limited by aerodynamic stability and space requirements of the powertrain, an analysis of which is outside the scope of this paper.

A large fan delivers the required initial climb thrust at lower shaft power than a small fan, i.e., more efficiently, as can be seen in Fig. 7. This is due to the generally better efficiency of propulsive devices featuring large cross sections at low flight speeds. As such, a larger fan, which requires less shaft power to fulfill the requirements, will also offer higher maximum thrust with the given powertrain and so improve aircraft climb rates.

However, this requires a large nacelle, which, at cruise conditions, contributes substantially to the airplane drag. A drag estimate based on the models presented in Sect. 3.2 is plotted in Fig. 7 to show this. With a fan diameter of $0.6 \mathrm{~m}$, the combined drag of both nacelles already amounts to $15 \%$ of the cruise thrust requirement. This increases to $26 \%$ for a diameter of $0.8 \mathrm{~m}$. This means that the fan size must be 


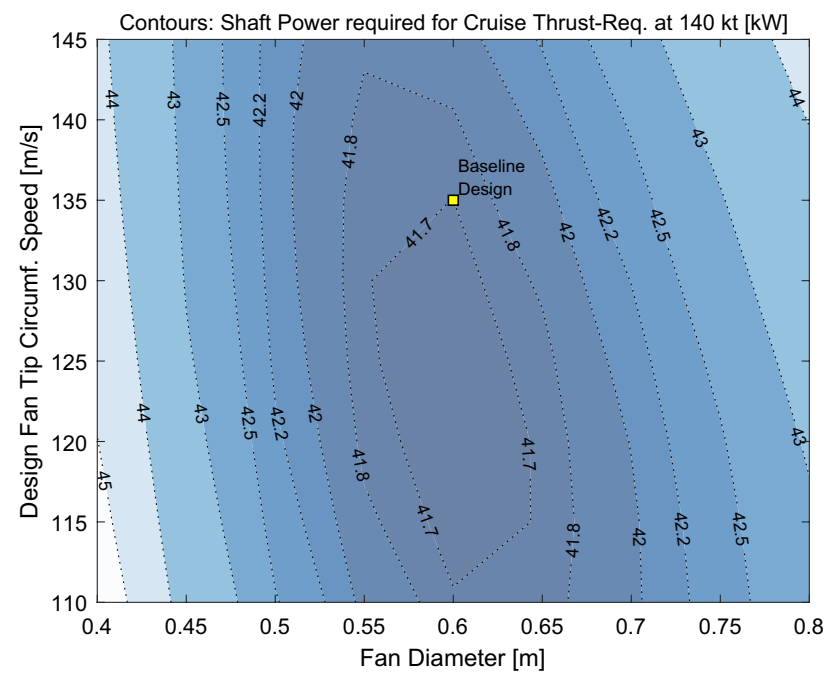

Fig. 8 Influence of fan diameter and tip speed on shaft power required to meet the cruise thrust requirement $(10 \mathrm{kft}, 140 \mathrm{kt})$

limited, so a diameter of $0.6 \mathrm{~m}$ has been chosen here as a compromise.

The fan diameter of $0.6 \mathrm{~m}$ is also a good choice, in view of shaft power demand, so that the required cruise thrust can be achieved, i.e., in terms of overall fan efficiency at this operating point. Figure 8 shows that the cruise fan shaft power is lowest at this diameter, although not very sensitive to either diameter or design tip speed. At relatively high cruise speeds, no propulsive efficiency advantage from larger fans can be observed, in contrast to the initial climb point. A smaller fan of $0.55 \mathrm{~m}$ diameter may offer better cruise performance when nacelle drag is taken into account. The larger diameter of $0.6 \mathrm{~m}$ is nevertheless better for initial climb performance; see Fig. 7.

The next parameter to be considered is tip speed. Besides its influence on efficiency, its implications on operational stability are of interest. Structural mechanics are not examined here, because this aspect is uncritical at the low blade speeds under consideration.

The design tip speed influences the blade shape. To perform the same work at a lower speed, the blades need to turn the flow more strongly. The camber line is then more curved, which affects loss generation and aerodynamic stability. When comparing the chosen design tip speed of $135 \mathrm{~m} / \mathrm{s}$ to the other options, an optimum is not easily identified. Lower design tip speeds reduce cruise power demand to some degree, but this is almost negligible (Fig. 8). However, reduced tip speeds also increase stage loading, which narrows the stable operating range.

Since the operating points throughout the flight mission are spread widely across the fan map (Fig. 6), it is difficult to ensure stable operation, including stability margins, under the most extreme conditions. The take-off condition is probably the most critical of the points considered, as the take-off points in the fan map are close to the surge line. Moreover, the take-off operating point must be maintained throughout the take-off roll, in contrast to the sea-level static point, which is closest to the surge line.

Stability is only discussed briefly here, since many factors must be taken into account for its assessment, including the flow near hub and tip, which is outside the scope of this paper. For a general illustration of the relationships, the mean line rotor de Haller number at take-off is shown in Fig. 9, depending on the design parameter choices. Lower design tip speeds and fan diameters decrease stability, because both increase blade loading. Since hub or tip sections can be more susceptible to flow instabilities, it can be argued that the mean line de Haller number should be kept above 0.8 . This is fulfilled for the baseline design parameter choice.

For stable operation, it is likewise sensible to minimize incidence. For all parameter combinations considered here, there is positive incidence at take-off. This is because the fan is strongly throttled at low inflow velocities. At cruise conditions, the opposite is the case. In this event, the fan is less throttled, as described in Sect. 4.2 in conjunction with the e-boost, and operates at negative incidence. The spread between these values decreases with increasing blade tip speed, i.e., rotational speed, and the map width increases accordingly. The selected design results in the operating point distribution shown in Fig. 6, which is considered to include sufficient stability margins.

Next, the influence of fan diameter and tip speed on noise emissions is discussed. In Fig. 10, the A-weighted overall sound power emitted by the fan is shown for the sea-level initial climb operating point with $1100 \mathrm{~N}$ thrust, so fulfilling

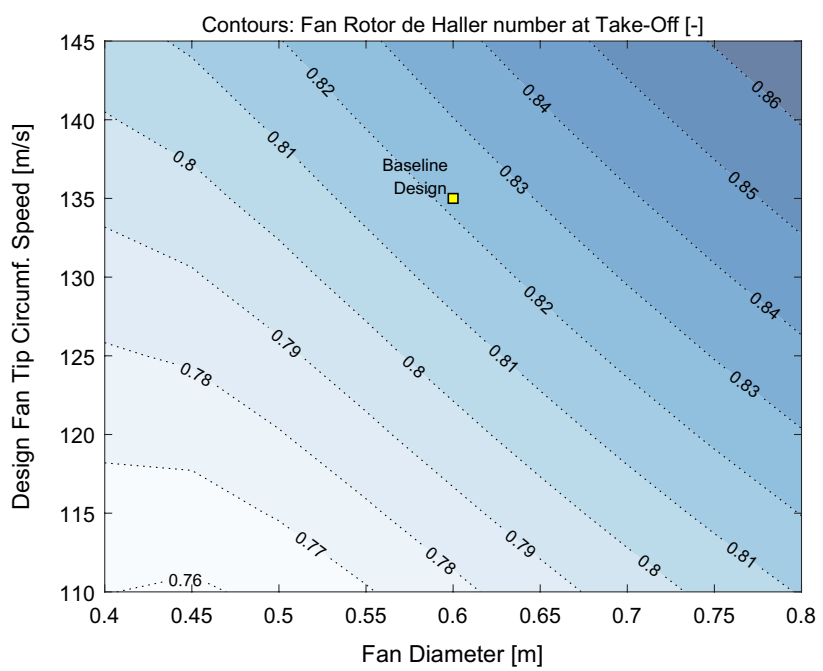

Fig. 9 Influence of fan diameter and tip speed on the fan rotor de Haller number at sea-level take-off thrust without e-boost 


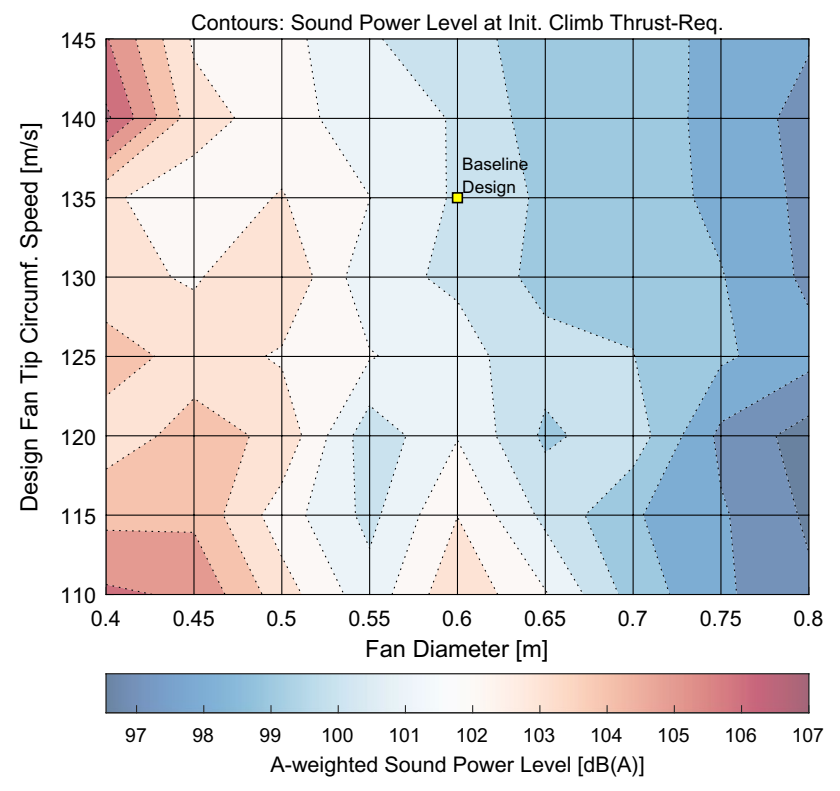

Fig. 10 Influence of fan diameter and tip speed on the A-weighted overall sound power level at sea-level initial climb required thrust. Grid intersections denote parameter combinations for which noise calculations have been carried out

the thrust requirement. Keeping the thrust constant for all design parameter choices ensures a fair comparison. The initial climb point is sensible for a fan noise comparison, because nearby residents are most exposed to noise shortly after take-off. Certification noise measurements are also carried out under such conditions [25].

The influence of blade tip speed on noise emissions depicted in Fig. 10 is only minor, with a barely discernible trend towards higher noise emissions at low blade tip speeds. The fan diameter has a strong influence on the noise emitted, ranging between 97 and $106 \mathrm{~dB}(\mathrm{~A})$ for the diameters which are considered here. These trends result from a combination of effects. First, lower tip speeds increase blade loading and blade loading increases noise. Since thrust is kept constant, larger fan diameters decrease loading and therefore noise. Furthermore, the ratio of axial gap to rotor chord is kept constant in this study, so the axial gap increases with diameter. This causes a stronger decay of unsteady-flow perturbations and reduces noise generation. Additionally, large fan tip diameters increase destructive radial interference, because higher blades, when the hub radius is kept constant, are more twisted. This results in greater cancellation of tonal noise, which is dominant.

There is no correlation between the overall sound power level and the helical tip Mach number. The helical tip Mach number is within the range of $0.3-0.5$ for all designs considered. This increases with rotational speed and decreases with fan diameter, due to the lower axial flow speed inside the larger fans. No corresponding trends of noise increase

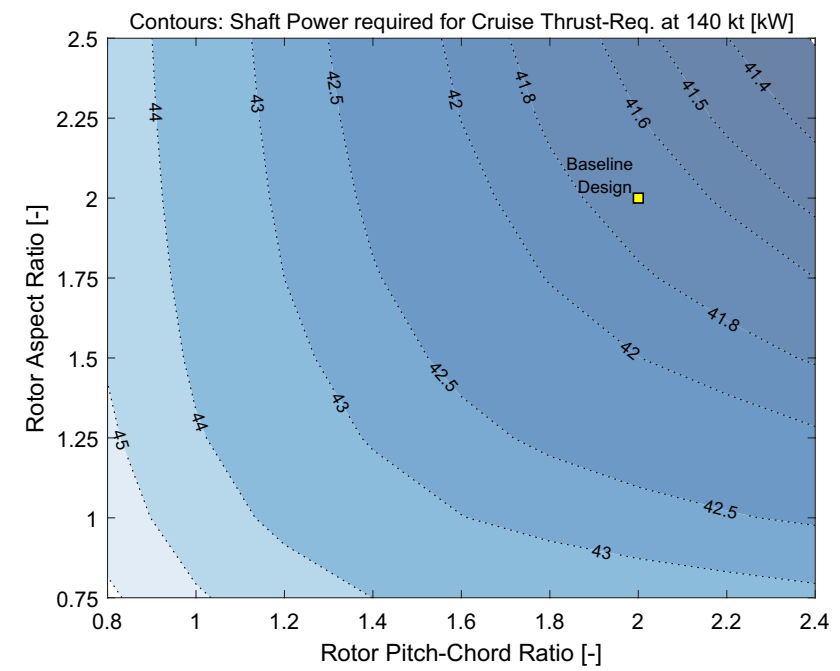

Fig. 11 Influence of rotor pitch-chord ratio and aspect ratio on shaft power required to meet the cruise thrust requirement (10 kft, $140 \mathrm{kt}$ )

or decrease can be seen in Fig. 10. At both points $(0.45 \mathrm{~m}$, $110 \mathrm{~m} / \mathrm{s})$ and $(0.7 \mathrm{~m}, 145 \mathrm{~m} / \mathrm{s})$, the helical tip Mach number is approximately 0.4 , but their noise levels differ by about $6 \mathrm{~dB}(\mathrm{~A})$.

\subsection{Blade aspect ratio and pitch-chord ratio}

Two further parameters to be investigated are the fan rotor pitch-chord ratio and aspect ratio. The impact of varying these parameters on the propulsion system performance is illustrated for the same operating points considered above. No additional variation of stator pitch-chord ratio or aspect ratio is presented here. These parameters have been investigated in more detail by Koppelberg et al. [30], with particular attention to the effect of blade/vane number combinations on acoustics. All parameters, apart from the aspect ratio and pitch-chord ratio, match the values in Table 2 and remain unchanged throughout the studies.

The influence of both parameters on the shaft power required for cruise operation is visualized in Fig. 11. Generally speaking, higher aspect ratios are advantageous due to lower secondary losses. Higher pitch-chord ratios enable better efficiency due to lower profile losses. The baseline design choice is favorable in both respects.

For pitch-chord ratios above one, considerably reduced flow turning can occur at operating points with high blade incidence angles. This reduces the map width and influences the slope of the speed lines. Both effects can be seen in Fig. 12. The reduced map width affects surge margin, especially at take-off conditions, but for the design in question, the surge margin appears sufficient. It could, however, be increased substantially when lowering the pitch-chord ratio to 1 , i.e., when doubling the number of rotor blades. 


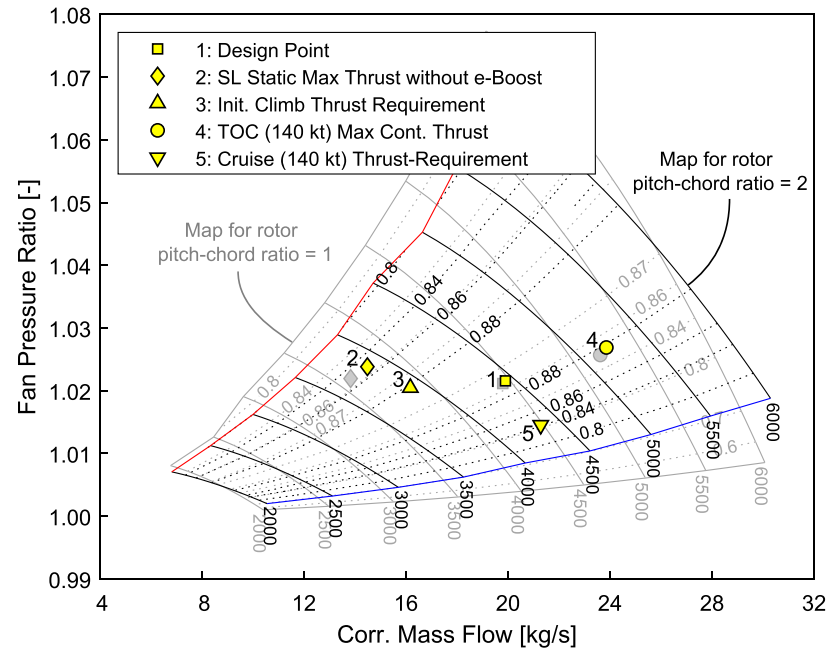

Fig. 12 Influence of rotor pitch-chord ratio on fan map width, speed line slope, and the location of various operating points, all without e-boost

Designing the fan with a larger rotor pitch-chord ratio, e.g., of 2, results in a map with flatter speed lines, as shown in Fig. 12. This offers a twofold advantage regarding the matching of fan and ICE.

Near the surge line, at operating points which are identical in terms of pressure ratio and mass flow, the fan featuring higher pitch-chord ratios operates at higher speeds. As such, when all other design parameters are equal, this fan can deliver more thrust in low ambient velocities, where available thrust is determined by the ICE torque limit. This improves take-off and initial climb performance. The higher pitch-chord ratio fan in Fig. 12 offers 10\% more sea-level static thrust.

Conversely, towards lower pressure ratios, the fan featuring a pitch-chord ratio of 2 operates at reduced speed compared to the one with a pitch-chord ratio of 1, due to the flatter speed lines. This reduces the ICE speed at high flight velocities, e.g., at cruise and TOC. For such operating points, the available thrust is usually determined by the ICE speed limit. Here too, the high pitch-chord ratio is therefore advantageous. It enables a higher thrust in cruising flight and thus ultimately higher cruising speeds. The higher pitch-chord ratio fan in Fig. 12 offers 5\% more TOC thrust.

Furthermore, when comparing the cruise operating points of both fans with pitch-chord ratios of 1 and 2, at the same flight speed and thrust, their mass flow and fan pressure ratios are identical. The fan with a pitch-chord ratio of 2, however, operates at lower spool speeds. Potentially therefore, the ICE can be more efficient and fuel consumption reduced, but this has not been observed in the present study. The higher pitch-chord ratio fan in Fig. 12 offers $4 \%$ less cruise fuel consumption, primarily as a result of better fan aerodynamic efficiency, whereas efficiency in the

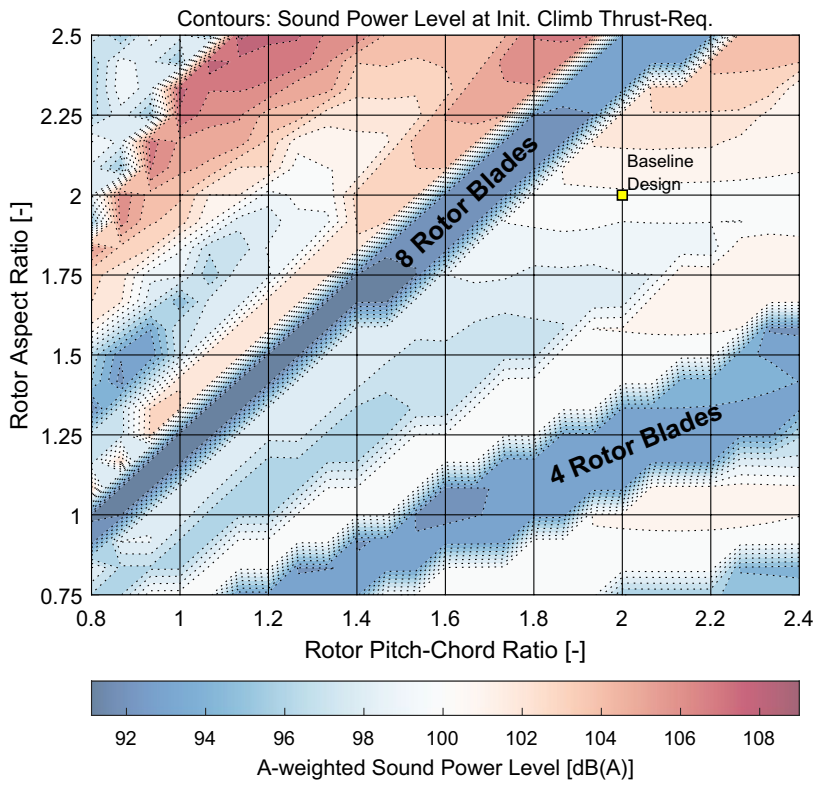

Fig. 13 Influence of rotor pitch-chord ratio and aspect ratio on the A-weighted overall sound power level at sea-level initial climb required thrust, for a fan design with 11 stator vanes. Grid intersections denote parameter combinations for which noise calculations have been carried out

cruise range of the ICE map is relatively insensitive to speed changes (see Fig. 5).

Next, the influence of varying aspect ratio and pitch-chord ratio on the noise emission is discussed. Since the blade number plays an important role for acoustics, the effect of changing the pitch-chord ratio and aspect ratio on rotor blade numbers must be taken into account. With fan hub and tip radii fixed, blade numbers vary considerably between the designs. On the diagonal running from the bottom left to top right in Fig. 13, the number of blades is about seven, as it is too for the baseline design. Above this diagonal, it rises up to 21 blades at point $(0.8,2.5)$. Below that, it drops down to two blades at point $(2.4,0.75)$. Not all of these numbers are within a practical range. High blade numbers entail higher costs and few blades with an extreme chord length take up too much axial space. Nevertheless, an investigation of their acoustic effects is still useful. Via the rotor-stator interaction, the blade number strongly influences noise generation.

Within the parameter range considered, the fan noise emitted varies considerably between 92 and $108 \mathrm{~dB}(\mathrm{~A})$. Along two lines of origin, the noise is particularly low. These correspond to eight rotor blades (upper line) and four rotor blades (lower line). Both blade numbers yield favorable blade/vane number combinations for a cut-off design, combined with 11 stator vanes. The first BPF is cut off with eight and less rotor blades. Hence, at nine blades, shortly before cut-off of the first BPF occurs, the noise generation 
is particularly strong. This is in line with theory [26]. Towards the blade number of five, the noise of the second BPF increases, before being cut off with four rotor blades. Despite the first and second BPF being cut off with four blades, the fan is no quieter than the one with eight. This is because the small aspect ratio necessary to achieve such a low blade number results in high chord lengths. These cause strong wakes, which increase overall noise generation.

Even with seven blades, the ducted fan noise is well below current certification standards, as shown by the following estimation. Assuming the ducted fan was to be evaluated as a ducted propeller, the requirements of ICAO Annex 16, Chapter 10 [25], apply. Noise is then assessed by means of a single measurement taken on the ground, in extension of the runway centerline, $2500 \mathrm{~m}$ after the brakes have been released, with the limit being $78.7 \mathrm{~dB}(\mathrm{~A})$. The two-seater aircraft under consideration here can climb about $160 \mathrm{~m}$ to this point, if the initial climb thrust without e-boost is applied on its own and the climb gradient is $8.3 \%$. The overall sound power level emitted per fan is $101 \mathrm{~dB}(\mathrm{~A})$ at this point.

The sound pressure level on the ground can be approximated as follows: Since the airplane is propelled by two fans, the calculated noise level increases by $3 \mathrm{~dB}$. A directional factor of $10 \mathrm{~dB}$ can be applied, since the ducted fan radiation pattern is unknown. An absorption of $1 \mathrm{~dB}$ per $100 \mathrm{~m}$ can be assumed, decreasing the sound pressure level by $1.6 \mathrm{~dB}$. Finally, the sound propagation at a distance of $160 \mathrm{~m}$ decreases the sound pressure level by $55.1 \mathrm{~dB}$. The sound pressure level measured on the ground, when the aircraft passes $160 \mathrm{~m}$ above, can therefore be estimated as power level minus $43.7 \mathrm{~dB}$, which yields $57.3 \mathrm{~dB}(\mathrm{~A})$. This is well below the ICAO limit, and further noise reductions are possible. According to Fig. 13, the baseline design noise emissions at initial climb could be reduced by another $8 \mathrm{~dB}(\mathrm{~A})$ if just one rotor blade was added to increase the blade number from seven to eight. With the aspect ratio kept constant, this increases cruise shaft power by about $1 \%$, which could be acceptable when low noise emission is a priority. Further noise reductions are possible, e.g., by fitting acoustic liners (not taken into account here). Additionally, the climb procedure could be adapted, e.g., using the e-boost for a steeper climb.

\subsection{Nozzle diameter}

The final design parameter to be considered is the nozzle diameter, which is expressed here in relation to the fan diameter. Large nozzle diameters offer better propulsive efficiency through increased fan mass flows and, in turn, higher thrust at low flight speeds. At high flight speeds however, due to the ram pressure, the fan must be throttled sufficiently by the nozzle to achieve a fan pressure ratio greater than 1 , so as to generate thrust. This cannot be achieved by increasing fan spool speed alone, since the available spool speed range is limited by the ICE. Without sufficient throttling of the fan, flow separation on the blade pressure side occurs due to strong negative incidence. Sensible nozzle/fan diameter ratios are therefore below 1 for fixed wing aircraft, while they can be above 1 for vertical take-off and landing aircraft with much less intake ram pressure during cruise.

The baseline design choice of 0.9 (Fig. 14) favors cruise over initial climb efficiency and was made with the aforesaid consideration in mind. It leads to acceptable operating point locations in the fan map (Fig. 6). In addition, the resulting convergence of the nacelle contour is still sufficiently small to avoid flow separation.

\section{Summary and outlook}

With the mission requirements and boundary conditions given, especially in the absence of a variable blade pitch mechanism, the hybridization of the ducted fan propulsion system offers significant advantages. Supplying the ICE with electric power at take-off solves the matching problem of ICE and fixed pitch ducted fan, namely, that such a fan optimized for cruise efficiency and TOC thrust cannot extract maximum ICE power at take-off. For every $2 \mathrm{~kW}$ of electric power supplied at take-off, the sped-up ICE can provide about $1 \mathrm{~kW}$ more power than without e-boost, so $2 \mathrm{~kW}$ of electrical power translates to roughly $3 \mathrm{~kW}$ fan shaft power.

Furthermore, for ICE-driven fixed pitch fans with operating points widely spread over the fan map-e.g., in high cruise speed applications - a rotor design with high pitch-chord ratios is advantageous. Reduced flow turning

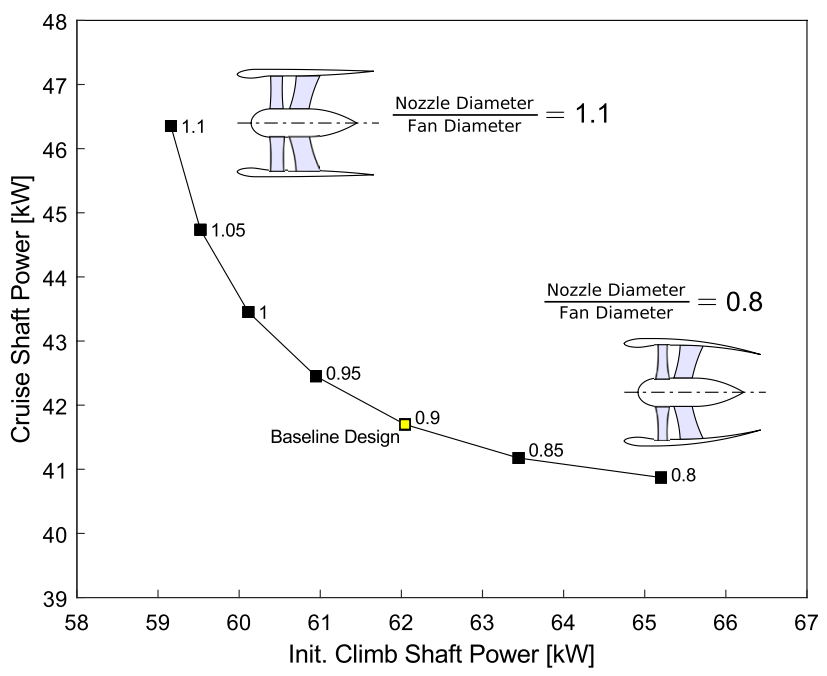

Fig. 14 Fan shaft power needed to fulfill the thrust requirements at init. climb and cruise, depending on nozzle diameter 
due to incidence-dependent deviation then partially compensates for the lack of blade pitch adjustment.

Noise emissions for the propulsion system design example analyzed are predicted to be $20 \mathrm{~dB}(\mathrm{~A})$ below ICAO noise limits. It seems realistic to design ducted fans of more than $20 \mathrm{~dB}$ (A) below these limits, provided that noise sources neglected in this publication, e.g., intake distortion, can be controlled and remain of minor magnitude. Ducted fan propulsion systems, especially hybrid ones, can thus be a sensible alternative to free propellers for certain applications, particularly if low noise emissions are required.

Even small design modifications, especially regarding blade and vane numbers, can change noise emissions of ducted fans, such as the one under consideration here, by more than $10 \mathrm{~dB}(\mathrm{~A})$. There is also a trade-off between noise and efficiency. During the preliminary design, one can be optimized at the expense of the other. When noise reduction is a design goal, understanding the interdisciplinary relationships within the propulsion system is essential. Physicsbased methods like the one presented here provide a suitable approach to this.

Subsequent publications will address how noise at different operating points is affected by the design parameters. Further optimization potential may be found when varying additional propulsion system and blade design parameters. Higher fidelity methods will be applied on the same design for a comparison of results.

Funding Open Access funding enabled and organized by Projekt DEAL.

Open Access This article is licensed under a Creative Commons Attribution 4.0 International License, which permits use, sharing, adaptation, distribution and reproduction in any medium or format, as long as you give appropriate credit to the original author(s) and the source, provide a link to the Creative Commons licence, and indicate if changes were made. The images or other third party material in this article are included in the article's Creative Commons licence, unless indicated otherwise in a credit line to the material. If material is not included in the article's Creative Commons licence and your intended use is not permitted by statutory regulation or exceeds the permitted use, you will need to obtain permission directly from the copyright holder. To view a copy of this licence, visit http://creativecommons.org/licenses/by/4.0/.

\section{References}

1. Akustik - Bestimmung der Lärmexposition am Arbeitsplatz Verfahren der Genauigkeitsklasse 2 (Ingenieurverfahren) (ISO 9612:2009)

2. Berdrow, B., Busch, E., Grünewald, B.H., Heine, S., Krämer, U., Zimmermann, K., Giese, P., Schmidt-Stiebitz, P., Limbach, P., Welbhoff, F., Mühlbauer, G., Schrecker, H., Neuwerth, G., Kellner, A.: Leiser Antrieb für die allgemeine Luftfahrt:
Schlussbericht über die Definitionsphase. Bundesministerium für Forschung und Technologie, Forschungsbericht W 77-23, Bonn (1977)

3. Blackaby, J.R., Watson, E.C.: An experimental investigation at low speeds of the effects of lip shape on the drag and pressure recovery of a nose inlet in a body of revolution. NACA Technical Note TN 3170, Washington. D.C. (1954)

4. Bogdański, K., Krusz, W., Rodzewicz, M., Rutkowski, M.: Design and optimization of low speed ducted fan for a new generation of joined wing aircraft. In: 29th Congress of the International Council of the Aeronautical Sciences (ICAS), St. Petersburg, Russia, 7-12 September 2014 (2014)

5. Borer, N.K., Patterson, M.D., Viken, J.K., Moore, M.D., Bevirt, J., Stoll, A.M., Gibson, A.R.: Design and performance of the NASA SCEPTOR distributed electric propulsion flight demonstrator. In: 16th AIAA Aviation Technology, Integration, and Operations Conference (AIAA AVIATION Forum), Washington, DC, USA, 13-17 June 2016 (2016)

6. Böswirth, L., Bschorer, S., Buck, T.: Technische Strömungslehre: Lehr- und Übungsbuch, 10th rev. and exp edn. Springer Vieweg, Wiesbaden (2014)

7. Brelje, B.J., Martins, J.R.: Electric, hybrid, and turboelectric fixed-wing aircraft: a review of concepts, models, and design approaches. Prog. Aerosp. Sci. 104, 1-19 (2019)

8. BRP-Rotax GmbH \& Co. KG: Operators Manual for Rotax Engine Type 915 iS A Series. Ed.0, Rev.1, June 1, 2019 (2019)

9. Brüning, G., Hafer, X., Sachs, G.: Flugleistungen: Grundlagen, Flugzustände, Flugabschnitte; Aufgaben und Lösungen, 3rd, exp. new edn. Springer, Berlin and others (1993). In collab. with W. Jurzig

10. Carolus, T.H.: Ventilatoren,: Aerodynamischer Entwurf, Schallvorhersage, Konstruktion, 3rd rev. and exp. edn. Vieweg+Teubner, Wiesbaden (2013)

11. Castegnaro, S.: Aerodynamic design of low-speed axial-flow fans: a historical overview. Designs 2(3), 20 (2018)

12. Davis, D.G.M.: Ducted propulsors for general aviation. Aircr. Eng. Aerosp. Technol. 49(9), 5-7 (1977)

13. Decher, R., Gillette, W., Koncsek, J., Marshall, F., Ridgeway, R., Salemann, V.: System aspects of engine installation. In: Oates, C. (ed.) The Aerothermodynamics of Aircraft Gas Turbine Engines, Technical Report AFAPL-TR-78-52. Wright-Patterson AFB, OH (1978)

14. Denton, J.D.: Loss mechanisms in turbomachines. J. Turbomach. 115(4), 621-656 (1993)

15. Dixon, S.L., Hall, C.A.: Fluid Mechanics and Thermodynamics of Turbomachinery, 7th edn. Elsevier, Amsterdam (2014)

16. e.SAT GmbH: Silent Air Taxi (2020). https://e-sat.de/de/silentair-taxi/. Retrieved 17 Aug 2020

17. European Aviation Safety Agency: Certification Specifications for Normal-Category Aeroplanes CS-23: Amendment 5 (2017)

18. FanJet Aviation GmbH: Fanjet 600 (2020). http://www.fanje taviation.com/. Retrieved 17 Aug 2020

19. Frediani, A., Cipolla, V., Oliviero, F.: IDINTOS: the first prototype of an amphibious PrandtlPlane-shaped aircraft. Aerotec. Missili Spazio 94(3), 195-209 (2015)

20. GasTurb GmbH: Gas turbine performance software (2020). https://gasturb.de/. Retrieved 19 Aug 2020

21. Gudmundsson, S.: General Aviation Aircraft Design: Applied Methods and Procedures, 1st edn. Butterworth-Heinemann, Oxford (2014)

22. Hahn, A.S.: Next generation NASA GA advanced concept. SAE Technical Paper 2006-01-2430. SAE International, Warrendale, PA (2006)

23. Hoerner, S.F.: Fluid-Dynamic Drag: Practical Information on Aerodynamic Drag and Hydrodynamic Resistance. Hoerner Fluid Dynamics, Bakersfield (1965) 
24. Hubbard, H.H., Lansing, D.L., Runyan, H.L.: A review of rotating blade noise technology. J. Sound Vib. 19(3), 227-249 (1971)

25. International Civil Aviation Organization (ICAO): Annex 16 to the Convention on International Civil Aviation: Environmental Protection: Volume I Aircraft Noise, 7th edn. ICAO, Montréal (2014)

26. Jaron, R.: Aeroakustische Auslegung von Triebwerksfans mittels multidisziplinärer Optimierungen. Ph.D. thesis, TU Berlin (2018)

27. Joubert, E., Chapuis, D., Esteyne, D., Lambert, J.C., Siri, O., Müller-Wiesner, D.: The E-Fan all electrical aircraft demonstrator and its industrialization. In: 30th Congress of the International Council of the Aeronautical Sciences (ICAS), Daejon, Korea, September 25-30 2016 (2016)

28. Kerrebrock, J.L.: Aircraft Engines and Gas Turbines, 2nd edn. MIT Press, Cambridge (1992)

29. Khalid, M.: Qss Toolbox. MATLAB Central File Exchange. https://www.mathworks.com/matlabcentral/fileexchange/73483qss-toolbox. Retrieved 12 Aug 2020

30. Koppelberg, J., Weintraub, D., Jeschke, P.: Acoustic pre-design studies of ducted fans for small aircraft [Manuscript in preparation]. Institute of Jet Propulsion and Turbomachinery, RWTH Aachen University, Aachen (2021)

31. Lewis, R.I.: Turbomachinery Performance Analysis. Arnold, London (1996)

32. Lieblein, S.: Experimental flow in two-dimensional cascades. In: Johnsen, I.A., Bullock, R.O. (eds.) Aerodynamic Design of AxialFlow Compressors. Technical Report NASA SP-36. National Aeronautics and Space Administration, Cleveland, OH (1965)

33. Moore, M.D.: Misconceptions of electric aircraft and their emerging aviation markets. In: 52nd Aerospace Sciences Meeting (AIAA SciTech Forum), National Harbor, MD, USA,13-17 January 2014 (2014)

34. Moreau, A.: A unified analytical approach for the acoustic conceptual design of fans of modern aero-engines. Ph.D. thesis, TU Berlin (2017)
35. Neise, W., Michel, U.: Aerodynamic noise of turbomachines. DLR Internal Report 22314-94/B5. German Aerospace Center (DLR), Berlin (1994)

36. de Piolenc, F.M., Wright, G.E., Jr.: Ducted Fan Design: Volume 1. CreateSpace Independent Publishing Platform, Scotts Valley (2001)

37. Schade, S., Jaron, R., Moreau, A., Guérin, S.: Mechanisms to reduce the blade passing frequency tone for subsonic low-count OGV fans. Aerosp. Sci. Technol. (2021, in press)

38. Seddon, J., Goldsmith, E.L.: Intake Aerodynamics. AIAA and Blackwell Science, Washington (1985)

39. Stanhope, F.W.: The performance of NACA-1-series intakes. Rolls-Royce Power Plant Research Report IAR 85002, Rolls Royce, UK (1968)

40. The MathWorks, Inc.: MATLAB (2020). https://de.mathworks. com/products/matlab.html. Retrieved 14 July 2020

41. Torenbeek, E.: Synthesis of Subsonic Airplane Design. University Press, Delft (1976)

42. Traupel, W.: Thermische Turbomaschinen, 3rd rev. and exp Springer, Berlin (1988). Corrected reprint

43. Watzlawick, R.: Untersuchung der wesentlichen Einflussfaktoren auf die Sekundärverluste in Verdichter- und Turbinengittern bei Variation des Schaufelseitenverhältnisses. Ph.D. thesis, Universität der Bundeswehr, München (1991)

44. Wilson, M.: Dowty ducted propulsor flies. FLIGHT Int. 112, 209-211 (1977)

45. Youngren, H., Drela, M., Sanders, S.: Ducted Fan Design Code (DFDC) (2005). https://web.mit.edu/drela/Public/web/dfdc/. Retrieved 17 Aug 2020

46. Zhang, T., Barakos, G.N.: Review on ducted fans for compound rotorcraft. Aeronaut. J. 124(1277), 941-974 (2020)

Publisher's Note Springer Nature remains neutral with regard to jurisdictional claims in published maps and institutional affiliations. 